\title{
Coronary artery bypass graft using the right coronary artery-pulmonary artery fistula
}

\author{
Luís A. Dallan, MD, Luiz Augusto F. Lisboa, MD, Carlos Alberto C. Abreu Filho, MD, \\ Fernando Platania, MD, and Sérgio Almeida De Oliveira, MD, São Paulo, Brazil
}

W e report the case of a 72-year-old man with a congenital coronary fistula between the right coronary artery (RCA) and the main pulmonary artery (PA) associated with coronary atherosclerosis. He remained asymptomatic until 72 years of age, when myocardial ischemia developed. Myocardial revascularization was performed using four saphenous vein grafts. In addition, the coronary fistula was dissected, distally sectioned, and also used as a graft to a suboccluded coronary artery branch.

\section{Clinical Summary}

A 72-year-old man with a history myocardial ischemia was admitted at our hospital for management of unstable angina. He was asymptomatic but recently had had progressive chest pain. Coronary angiography revealed severe atherosclerotic coronary artery disease associated with an RCA-PA fistula (Figure 1). Coronary artery catheterization showed proximal stenosis in both the left anterior descending coronary artery and the circumflex coronary artery; it also revealed stenosis in the middle segment of the RCA distal to the fistula, with involvement of the right marginal branch.

After providing informed consent, the patient underwent coronary artery bypass grafting through a sternotomy in June 1991, with cardiopulmonary bypass and intermittent aortic clamping. Four saphenous veins grafts were made to the left anterior descending coronary artery, the diagonal artery, the circumflex coronary artery, and the RCA. After careful dissection and identification of the RCA-PA fistula ( $3 \mathrm{~mm}$ in diameter), it was ligated and cut close to the PA. The distal portion of the coronary fistula was dissected gently and anastomosed to the right marginal branch as an arterial graft to supply blood to the right ventricular wall. Electrocardiography revealed no ischemic changes, and the patient had an uneventful postoperative course. He was discharged in good clinical condition.

Repeat angiography, performed 6 months postoperatively, showed that the coronary arterial fistula graft to the right marginal

From the Heart Institute (InCor), University of São Paulo Medical School, São Paulo, Brazil.

Received for publication May 3, 2004; accepted for publication May 10, 2004.

Address for reprints: Luís Alberto O. Dallan, MD, Av. Inhambu, 917 Ap. 191, São Paulo, SP, 04520-013, Brazil (E-mail: dcidallan@incor.usp.br).

J Thorac Cardiovasc Surg 2005;129:225-6

$0022-5223 / \$ 30.00$

Copyright $\odot 2005$ by The American Association for Thoracic Surgery

doi:10.1016/j.jtcvs.2004.05.015 branch was patent (Figure 2). The saphenous vein grafts were also patent, and the patient was healthy. During 11 years of follow-up, the patient had an excellent quality of life without subsequent cardiac events. He died in April 2002 at the age of 83 years, and no autopsy was performed.

\section{Discussion}

Coronary artery fistulas are rare anomalies and usually congenital. Most occur as a single fistula, with $90 \%$ of them draining into the right side of the heart or the PA. ${ }^{1,2}$ The flow of blood through the fistula into a low-pressure right-heart chamber causes myocardial ischemia both by producing a coronary steal and by imposing an additional volume load on the left ventricle. Elective closure in childhood has been advocated to prevent later complications, such as congestive heart failure, myocardial ischemia, bacterial endocarditis, fistula rupture, or aneurysmal dilatation during or after the second decade of life. ${ }^{2,3}$

A continuous murmur is the classic physical finding, but in some instances the fistula might be associated with other cardiac disease and detected as an incidental finding on an echocardiogram. ${ }^{1,4}$ The diagnosis is confirmed during heart catheterization for congenital or coronary heart disease. There is no specific medical therapy for coronary fistula other than management of coexisting congestive heart failure, yet in some cases the fistula can be treated by transcatheter embolization or surgical intervention. ${ }^{3,5,6}$ Some authors have advocated that asymptomatic patients with coronary artery fistulas be followed noninvasively without intervention. ${ }^{4}$ In our patient the RCA-PA fistula was an incidental diagnosis associated with the coronary atherosclerosis, and both conditions were surgically treated.

Our original goal was to perform myocardial revascularization and close the fistula through distal ligation during the same procedure. However, after gently dissecting the fistula away from the PA, we observed excellent blood flow from it, as we frequently see with internal thoracic artery grafts. Therefore, we decided to use the fistula as an arterial bypass graft to the important right marginal branch. After completing the anastomosis but before opening the aortic crossclamp, we observed good perfusion into the right marginal branch and satisfactory right ventricular contraction. It is possible that our ability to use the fistula as an arterial graft, as well its good blood flow, reflects the slow progressive enlargement of the fistula over time. Our initial surgical impression was confirmed by the favorable postoperative course and, 6 months later, by the results of the repeat coronary angiography.

In conclusion, we report the uncommon association of an RCA-PA fistula with severe coronary atherosclerosis in which the 


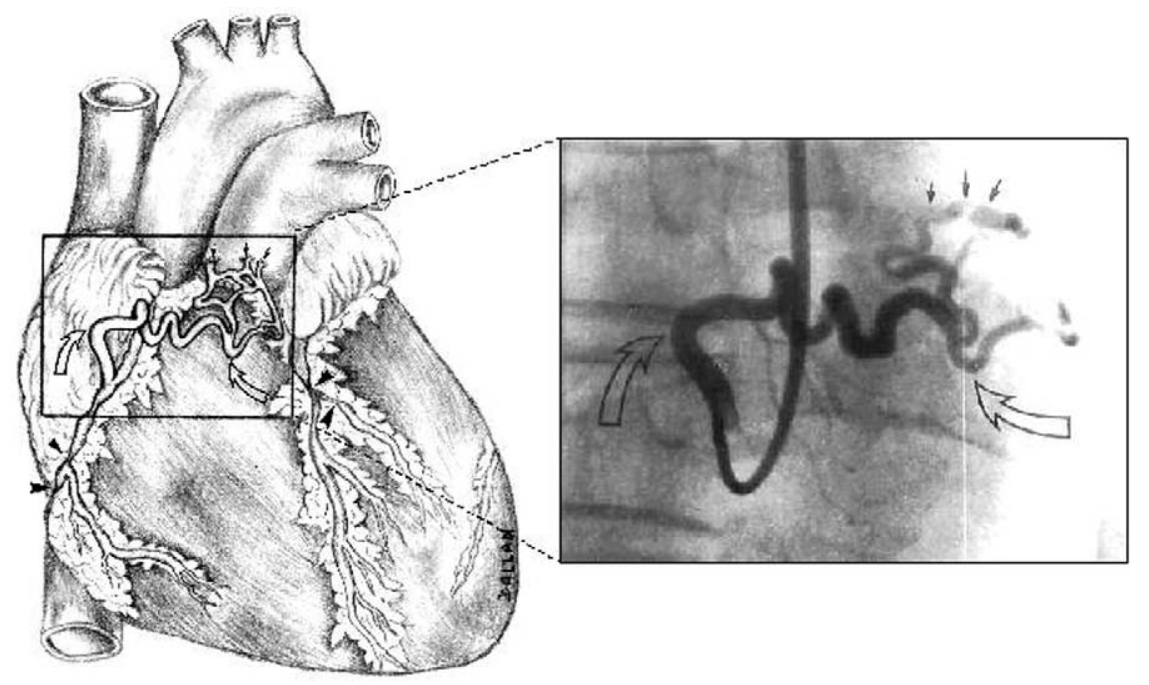

Figure 1. Preoperative cineangiocoronariography in the right oblique anterior projection showing the RCA-main PA fistula and the respective diagram.

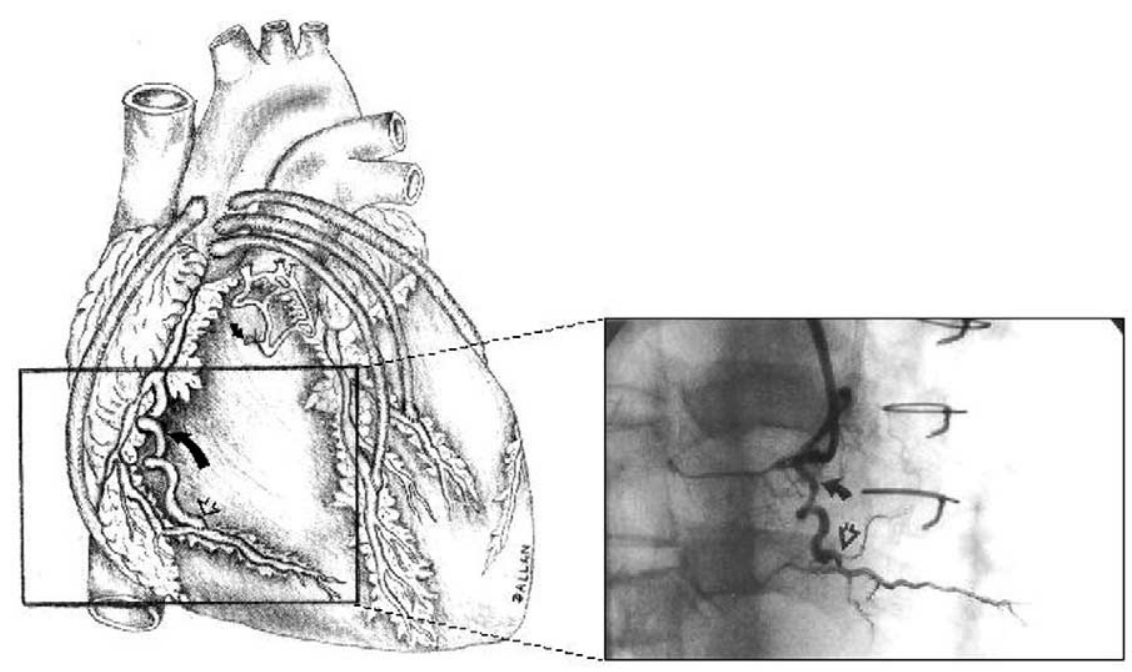

Figure 2. Postoperative cineangiocoronariography in the right oblique anterior projection showing patent coronary artery fistula grafted into the right marginal branch and the respective diagram.

fistula was successfully used as an arterial graft for myocardial revascularization.

\section{References}

1. Urrutian CO, Falaschi G, Ott DA, Cooley DA. Surgical management of 56 patients with congenital coronary artery fistulas. Ann Thorac Surg. 1983;35(3):300-7.

2. Liberthson RR, Sagar K, Berkoben JP, Weintraub RM, Levine FH. Congenital coronary arteriovenous fistula. Report of 13 patients, review of the literature and delineation of management. Circulation. 1979; 59(5):849-54.
3. Fernandes ED, Kadivar H, Hallman GL, Reul GJ, Ott DA, Cooley DA. Congenital malformations of the coronary arteries: the Texas Heart Institute experience. Ann Thorac Surg. 1992;54:732-40.

4. Sherwood MC, Rockenmacher S, Colan SD, Geva T. Prognostic significance of clinically silent coronary artery fistulas. Am J Cardiol. 1999;83:407-11.

5. Mavroudis C, Backer CL, Rocchini AP, Muster AJ, Gevitz M. Coronary artery fistulas in infants and children: a surgical review and discussion of coil embolization. Ann Thorac Surg. 1997;63:1235-42.

6. Reidy JF, Anjos RT, Qureshi SA, Baker EJ, Tynan MJ. Transcatheter embolization in the treatment of coronary artery fistulas. $J$ Am Coll Cardiol. 1991;18:187-92. 